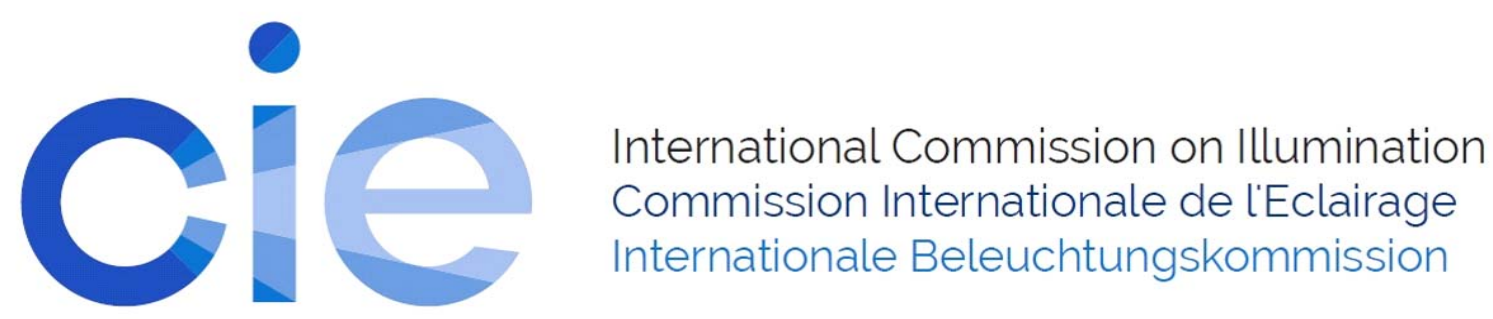

P0171

\title{
MODELLING OF LARGE LIGHT SOURCES RADIATION TO THE UPPER HEMISPHERE - OBTRUSIVE LIGHT \\ Tomas Novak et al.
}

DOI 10.25039/x46.2019.PO171

from

CIE x046:2019

Proceedings

of the

29th CIE SESSION

Washington D.C., USA, June 14 - 22, 2019

(DOI 10.25039/x46.2019)

The paper has been presented at the 29th CIE Session, Washington D.C., USA, June 14-22, 2019. It has not been peer-reviewed by CIE.

(C) CIE 2019

All rights reserved. Unless otherwise specified, no part of this publication may be reproduced or utilized in any form or by any means, electronic or mechanical, including photocopying and microfilm, without permission in writing from CIE Central Bureau at the address below. Any mention of organizations or products does not imply endorsement by the CIE.

This paper is made available open access for individual use. However, in all other cases all rights are reserved unless explicit permission is sought from and given by the CIE.

CIE Central Bureau

Babenbergerstrasse 9

A-1010 Vienna

Austria

Tel.: +4317143187

e-mail: ciecb@cie.co.at

www.cie.co.at 


\title{
MODELLING OF LARGE LIGHT SOURCES RADIATION TO THE UPPER HEMISPHERE - OBTRUSIVE LIGHT
}

\author{
Novak, T. ${ }^{1}$, Gasparovsky, D. ${ }^{2}$, Becak, P. ${ }^{3}$, Sokansky, K. ${ }^{4}$ \\ 1,3,4 VSB-TUO Faculty of Electrical Engineering and Computer Science, Ostrava, CZECH REPUBLIC, \\ ${ }^{2}$ Slovak University of Technology, Bratislava, SLOVAKIA,
}

tomas.novak1@vsb.cz

DOI 10.25039/x46.2019.PO171

\begin{abstract}
This article describes one possible way of conducting evaluation of lighting system in aspect of influence of emitted luminous flux on outdoor environment in upper hemisphere. It is focused on modelling, evaluation and limitations of obtrusive light on practical/everyday examples and applications. Nowadays information and discussions stimulated research to find "simple" model of radiation of luminous flux to the upper hemisphere. It means that the model will evaluate luminous flux (direct and reflected) not only generally, but to the affected directions too. The contribution describes how the model works. There is description of basic calculations of luminous flux radiation characteristic. Last parts of contribution try to shows example of real town lighting systems. Modelled example shows calculations of different lighting system like public lighting, billboards, windows and cars separately.
\end{abstract}

Keywords: Software Goniophotometer, Obtrusive Light, Public Lighting, Billboards, Windows, Headlamps, Luminous Flux, Radiation, Upper Hemisphere

\section{Public lighting and related, currently discussed topics}

Recently there has been a lot of media coverage related to obtrusive light viewed not only from quantitative and qualitative points of view. The above mentioned information usually come from astronomers, doctors and biologists recommendations who do not have any feedback on quantification of luminous flux outdoors [1,2]. Information presented in such a way often give the impression that outdoor lighting (mainly public lighting) is an unwanted phenomena which causes many lifestyle diseases. De-facto people usually disapprove with outdoor lighting at night ignoring its main purpose - which is a transfer of information to the brain in the best possible quality and highest possible speed, so that safety of people in a given illuminated area is ensured by visual perception.

Usually it is public lighting that is spoken about unfavourably, but other sources of obtrusive light are being forgotten. Such studies completely ignore standards as well as the fact that, even in the worst acceptable cases in city centres the limit of vertical illumination is $5 \mathrm{Ix}$ on the outside of a window [3]. If we take transmittance of the window, thin curtains and the distance of the eye from the window into account we get at most a half of the limit inside of the room, which means that astronomers prefer star visibility to human safety. Biologists claim that some organisms, such as insects for example, are more sensitive to shortwave radiation. Surely biologists are not keen on public lighting with colder sources, because apart from increasing human safety they also attract insects. Doctors, in turn, warn against the danger of blue part of spectrum in lighting systems in spite of researches which suggest that affecting the formation of the sleep hormone melatonin can only be achieved at high light levels, even at relatively short hourly exposures, as has been found in the past. Illumination levels up to $30 \mathrm{Ix}$ at any color of standard light do not have any effect on leaching of sleep hormone even at about an hour long exposures. [4]

The following figure shows the dynamics of lighting in our immediate surroundings during the day. Since receptors in human body respond to differences (not absolute values), it is necessary to evaluate the disturbing light in the night hours in relation to the lack of daylight. Insufficient leaching of sleep hormone is not treated with greater darkness at night, but with higher daytime illumination. 


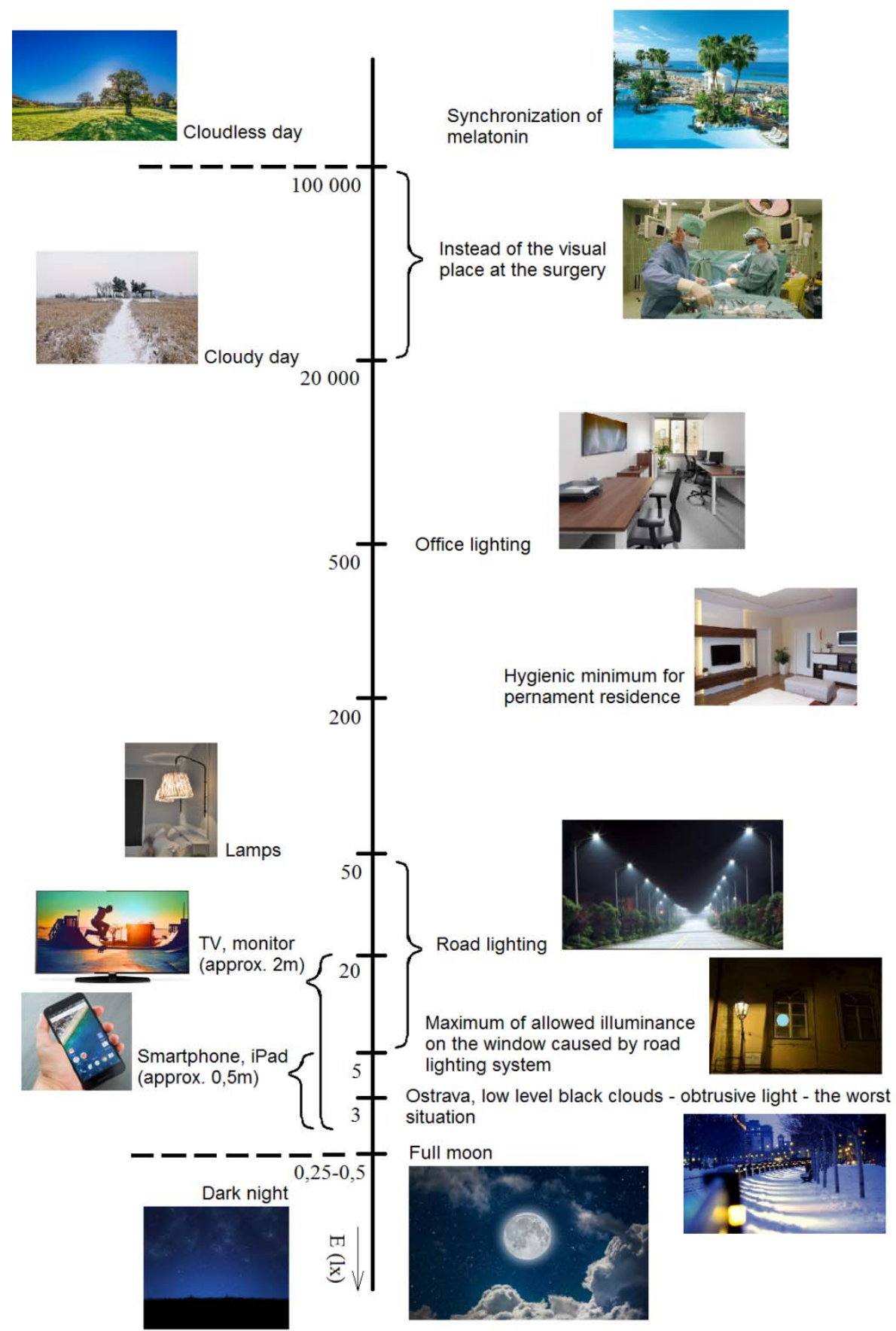

Figure 1 - Illuminance level in our neighborhood

If we talk about the so-called harmfulness in the sense of increased sky brightness it is necessary to take into account that the dispersion of radiation in the atmosphere depends indirectly on the fourth power of the wavelength - therefore the sky is blue (day and night).If the atmosphere is clean (free of dust and water particles), the radiation generated by ground sources shines into space and the sky brightness hardly increases at all (the stars are visible) and the reflected light component is almost unmeasurable ( $\mathrm{mlx}$ units). Thus, cloudiness and smog in particular contribute to the increased sky brightness in terms of higher reflected light intensities. Smog particles and vapours are significantly larger than the air molecules, so it is not possible to apply Rayleigh's theory to light scattering on these particles. The light scattering on these components will be similar in all visible spectrum components. However, we are still talking about $0,5 \mathrm{Ix}$ in the "affected" industrial areas. For the worst snow and snow cover conditions in industrial areas, horizontal illumination of up to $3 \mathrm{Ix}$ can be expected. And 
we can compare the EN 12464-2 table shows normative requirements for obtrusive light size according to the environmental characteristics. [3]

\subsection{The purpose of public lighting and its future}

Public lighting is a public service designed to increase safety, that is, it is designed to ensure the transfer of information to the brain. The rate of information transmission to the brain at optimal light conditions attacks the boundary of about 2,5 Mbps. Dependence is not linear, and the rate of transmission begins to drop dramatically below an illuminance value of about $500 \mathrm{~lx}$. Minimum requirements for internal illuminance levels are set at these levels. This means that the ratio of bit rate and electrical power consumption is acceptable. At lower illuminance values, the transmission speed slows down dramatically. In the field of public lighting, any reduction in illuminance (luminance) significantly reduces the transmission rate of information to the brain through vision. In connection with safety, transmission speed, or driver reaction times, it is necessary to point out that normative requirements are, like all standards, an acceptable minimum and not an attempt to limit the parameters of public lighting by authorities.

Since safety is directly related to the transmission of information, it is necessary to look for lighting conditions that will maximize this security. Public lighting occurs between daytime (photopic) and nighttime (scotopic) vision and is provided by two types of photoreceptors providing visual perception. Suppositories are dominantly distributed in the eye axis and provide axial vision, and rods, due to their distribution outside the eye axis, significantly increase the possibility of orientation through peripheral vision. Due to the fact that the maximum rod sensitivity is shifted to shorter wavelengths $(507 \mathrm{~nm})$, the visual error at low adaptation brightness and higher content of the shortwave component in the radiated spectrum is reduced and the road safety is increased. [4] Some may argue that the cooler colour of light is not, in combination with visual perception, aesthetically pleasing, but the priority of public lighting, especially when illuminating roads with low adaptation luminance and thus dark surroundings, is quite clear. There is no problem with the choice of warmer shades of light in city centres, which especially affect the visual comfort and people feel better in a similar way to home lighting and public areas where visual comfort is emphasized.

This means that ordering people what colour the light should be, limiting the replacement colour temperature, and limiting illuminance and luminance can lead to a reduction of safety when lighting darker, or confusing areas. It should also be noted that limiting the colour temperature would bring us to a standstill and would also block the creation of colour contrast when lighting pedestrian crossings, or bridges.

Another pressure made to limit public lighting is the strict prohibition of direct radiation to the upper half-space, respectively the order to install flat-glass luminaires and prohibition of their tilting. From a physical point of view, it is important to realize that a public lighting luminaire must radiate the dominant part of the luminous flux to the sides. This luminous flux must pass through an optical cover that provides both coverage and maintenance access to the luminaire. In the "preferred" flat glass, the beam must get through a significantly thicker glass than that of the convex glass which reduces efficiency of the luminaire. At large angles, the beams are reflected back into the luminaire and not on the road. It can be assumed that when the development of LEDs is finished, the manufacturers, in the context of the competition and increasing the efficiency of lighting systems, will use convex optical covers again, as these are more effective even in the case when a minor part of the light is radiated directly into the upper half-space (less than $1 \%$ ).Conversely, this flow (luminance of the luminaire) can be used advantageously for blind communications as a significant guidance element. It is also necessary to point out that the dominant part of the luminous flux that is emitted to the upper half-space from a public lighting system is not direct but reflected. It is up to about $20 \%$ of the total radiated luminous flux from lighting systems according to the type and reflectivity of the road and its surroundings. On the contrary, the direct luminous flux generated into the upper half-space is a luminous flux from skylights, windows, billboards, cars, etc., as the results of measuring in the past showed. $[5,6]$ 


\section{Historical measuring of the share of public lighting of obtrusive light}

As mentioned above in $[5,6]$ it is possible to draw conclusions from the measurement of switching off public lighting that at the beginning of the night the public lighting contributes to the luminous flux to the upper half-space by approx. $50 \%$.

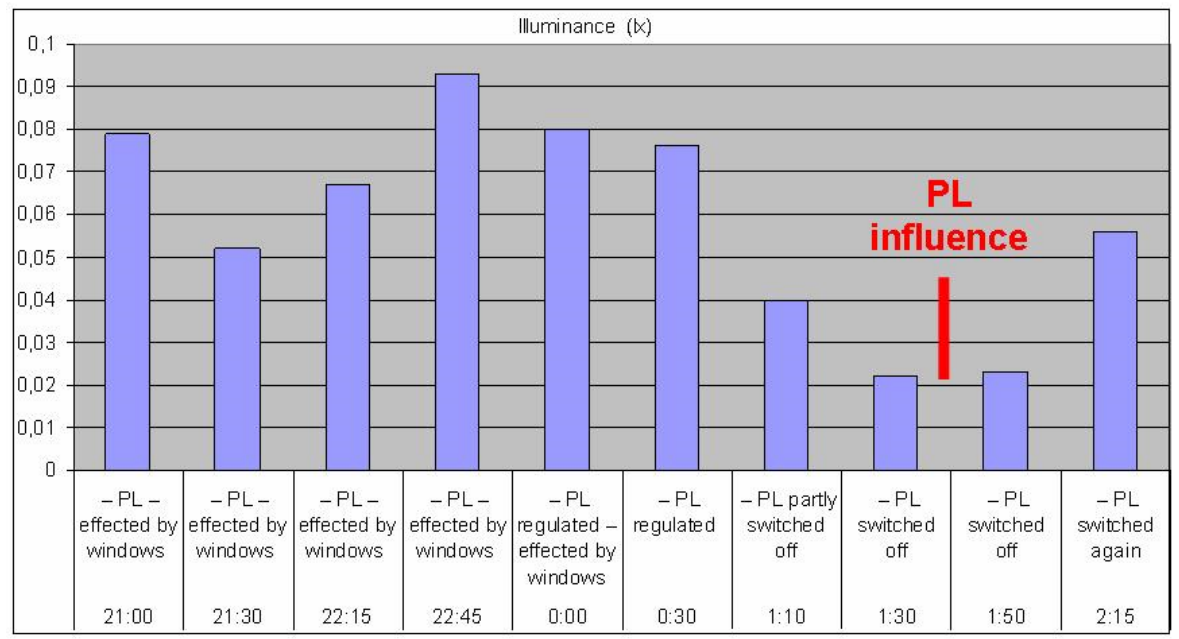

Figure 2 - Graph with measured illuminances in the centre of Liberec (city of the district) [5]

From the measurement results that $\mathrm{PL}$ in the big cities in the Czech Republic generate luminous flux to the upper hemisphere which increase sky luminances approximately about one third. With decreasing of the citizens numbers or decreasing of the part of industrial and shopping zones in the populated areas this part increasing. In the small villages is the part growing up and during the night can be up to $100 \%$.

Except expecting reflecting character variability of the night sky together with atmospheric conditions is during starting hours of the night showed strong influence of the windows in the residential sections on the sky luminances increasing. [5]

\subsection{Dynamics of night lighting in Ostrava}

From the point of view of the dynamics of the night sky, it is important to realize that the values of the horizontal illumination on an evenly cloudy sky are only in the values of lux units. [6]

Measured horizontal illuminance limit values at night:

- a clear moonless night - 0,001 Ix

- minimum value measured in Ostrava - clear sky - 0,02 Ix

- maximum value measured in Ostrava - snow cover with heavy snowfall - $3 \mathrm{Ix}$ 


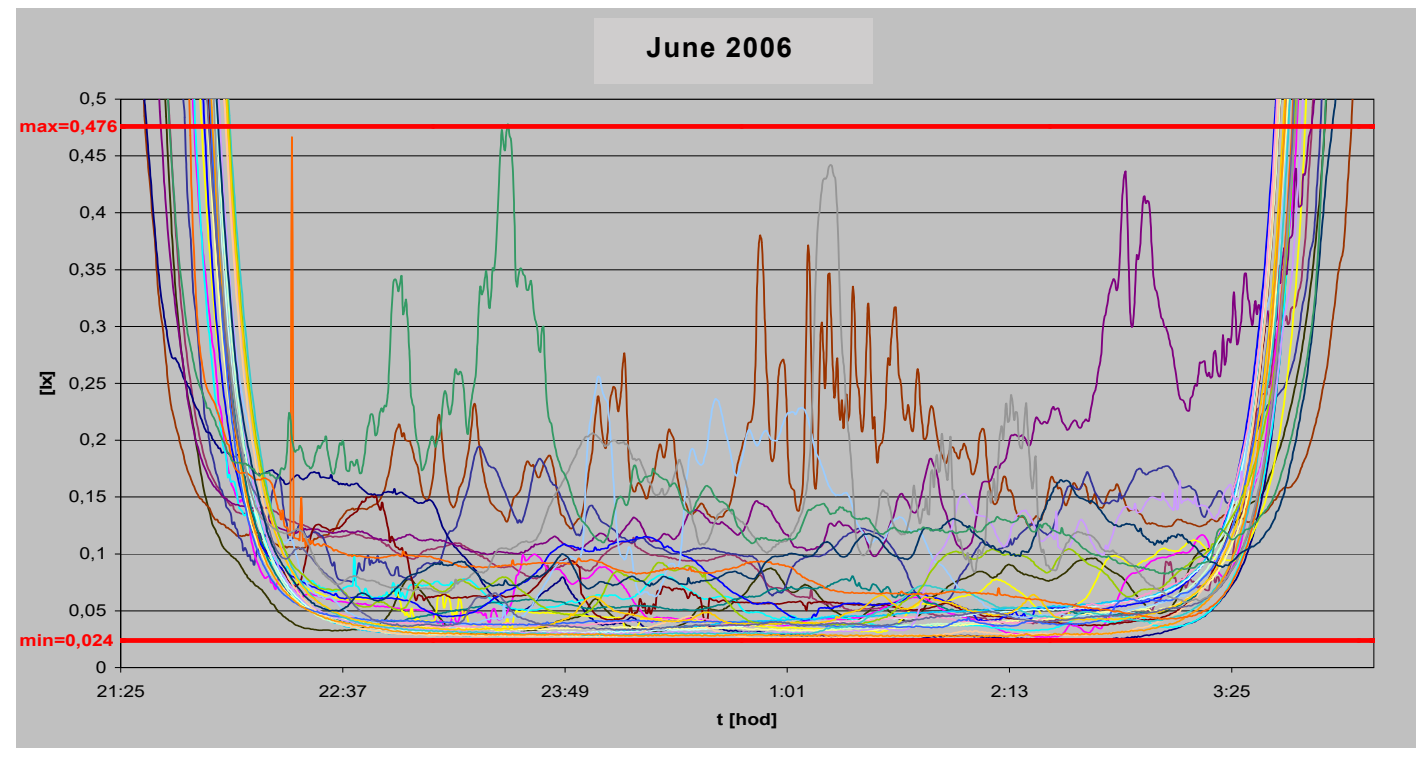

Figure 3 - Dependencies of night illuminance on time - June 2006 [6]

\section{Modeling of obtrusive light using a software goniophotometer}

This part of the article is description of the software goniophotometer possibilities. It will show modelling of the luminous flux in upper hemisphere generated by outdoor light sources. The model was prepared because of necessity to predict behaviour of lighting systems from the point of view obtrusive light. Until this time it was possible to do only some partial short or long term measurements mentioned above.

The Kolarikovo housing estate located in Frydek-Mistek was deliberately chosen for modeling because there is a large amount of lighting system with high-pressure sodium lamps in the shape of a sphere, which radiate a large proportion of their luminous flux into the upper halfspace. Therefore, we can say that this housing estate is a very bad example, because it contains a large number of unsuitable luminaires contributing significantly to the amount of disturbing light and the associated increased sky brightness. Obtrusive light cannot be completely prevented, but its effects can be greatly reduced by effective lighting. Only luminaires and lighting systems that do not directly radiate into the upper half-frame should be installed. Obtrusive light is not caused only by public lighting, but also by architectural lighting of buildings, illuminated signs (billboards), lighting of sports facilities and parking lots. It is also the light that escapes from interiors of high-rise buildings and residential buildings, as well as the light from car headlights. In general, all artificial lighting, not just public lighting, is a negative phenomenon and nowadays is a "thorn in astronomers and environmentalists side $"$.Therefore, it is necessary to verify all sources of obtrusive light and point out the fact that its magnitude is not caused only by public lighting.

Therefore the goal of modelling is to quantify several sources of disturbing light. First, the original HPS lighting system of public lighting then the replacement of this system by LED lighting system. Furthermore, the proportion of obtrusive light from windows, billboards and car headlamps should be quantified.

\subsection{Function of software goniophotometer}

Upgrade of software enable to insert calculation grid in sphere shape. Each calculated point describe normal illuminance in direction to the middle of sphere. This system duplicate function of the real goniophotometer. Principal of the goniophotometer is in possibility to measure luminous intensity in different levels and in different angles. It can be to interpret by sphere with calculation grid. The software goniophotometer duplicates this function only with difference, that is possible insert LDT file of luminaire or city LDT file with unbounded size. New possibility is option to choose density of calculation grid in angle step according standard used levels for luminaire measurement in C, y planes. For correct calculation it is necessary to take each object as simple point source. It means that object has insignificant dimensions 
against distance of point which is calculated. In praxis is this ratio requested higher than 5 so as light source was taken as simple point source. Figure 4 shows situation of simple point source (model of blocks of flats) regarding to calculation grid of the software goniophotometer. When the longest distance of model is $625 \mathrm{~m}$, then diameter of calculation points is $5000 \mathrm{~m}$. The distance is longer than requirement and that it is why the calculation fulfill needed condition. [7]
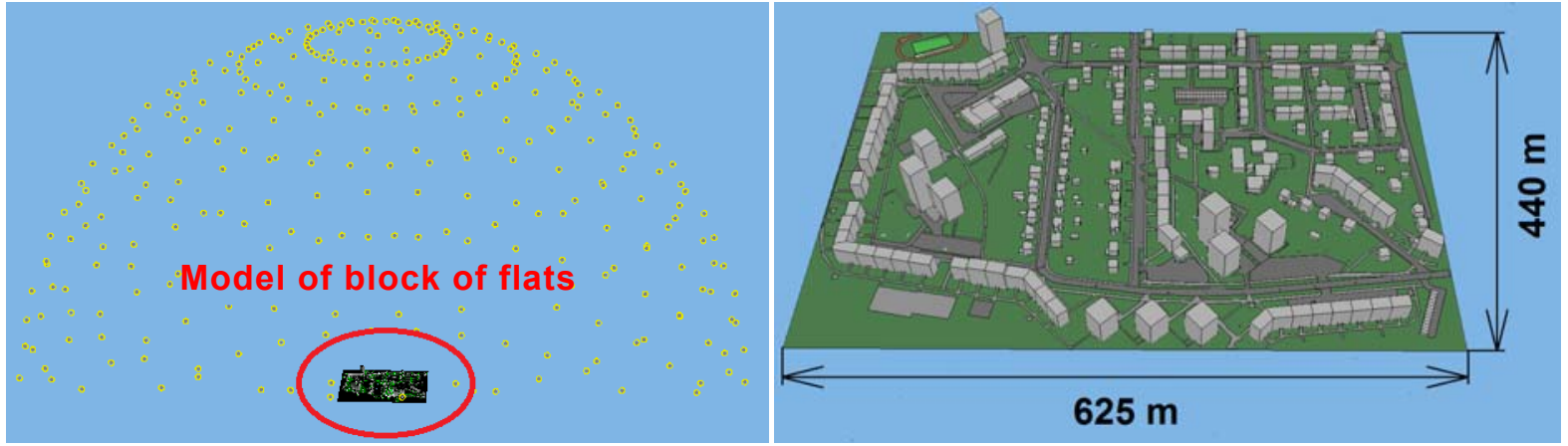

Figure 4 - Model of blocks of flats placed under the software goniophotometer

Software is working on basis of inverse square law (1). It means that each calculation point of the grid represented normal illuminance and after it is converted to luminous intensity in solved direction. Output is final luminous intensity distribution for whole calculated lighting system, which is possible exported to the LDT file. All calculations were done with maintenance factor 1 . It represent the worst case of the obtrusive light level. [7]

$$
E=\frac{I}{l^{2}}
$$

where

$$
\begin{array}{ll}
E & \text { Illuminance }(\mathrm{Ix}) ; \\
I & \text { Luminous intensity (cd); } \\
\text { l } & \text { Distance }(\mathrm{m}) .
\end{array}
$$

\subsection{The district with blocks of flats Kolarikovo description}

Basis for model is part of town Frydek-Mistek with roads and build up area. The district is placed on GPS coordinates $49^{\circ} 40^{\prime} 30.4^{\prime \prime N ~} 18^{\circ} 20^{\prime} 03.6 " \mathrm{E}$. Build up area is generally formed by blocks of flats and family houses. All surfaces like roads, houses and green spaces are described by their average reflectivity. Specification of it is in table 1.

Table 1 - Objects parameters calculated in model

\begin{tabular}{|l|l|l|l|}
\hline Objects & Count $(\mathrm{pcs})$ & Surface $\left(\mathrm{m}^{2}\right)$ & Reflectivity $(\%)$ \\
\hline Buildings & 170 & - & 30 \\
\hline Roads and parking places & - & 50000 & 10 \\
\hline Footpaths & - & 11000 & 20 \\
\hline Grass & - & 137000 & 10 \\
\hline HPS luminaires & 192 & - & - \\
\hline LED luminaires & 141 & - & - \\
\hline Cars - headlamps & 20 & - & - \\
\hline Billboards & 20 & - & - \\
\hline Windows & 217 & - & - \\
\hline
\end{tabular}


The HPS lighting system was inserted into the model by means of individual LDT file of the luminaire on the given position based on the dwg file, by means of which we also inserted buildings, roads, grassed areas, etc. The model features 192 luminaires, 94 of which are ballshaped luminaires that radiate $50 \%$ of the luminous flux into the upper half-space. The next step was to replace this outdated system of public lighting for a modern LED. The replacement was based on the luminous flux into the lower half-space of the original lighting system. There are 141 luminaires in this newly created system, that do not emit any amount of luminous flux into the upper half-space. Other sources of obtrusive light entering the calculation are windows and billboards. These models were created on the basis of luminance analysis of several samples and LDT file were created using the band-factor method with respect to the cosine radiation characteristic. 217 windows were placed randomly on the building's facades. The same was done for billboards. As there are no illuminated billboards in the housing estate, 10 billboards respecting the brightness of $20 \mathrm{~cd} \times \mathrm{m}^{-2}$ and 10 billboards with a brightness of $50 \mathrm{~cd} \times \mathrm{m}^{-2}$ were inserted. As the last source of disturbing light there are cars that respect low beams. The radiation characteristics of the two headlamps were measured on a photometric bench and then recalculated together to allow the insertion of one LDT file defining 1 car. Even this recalculation, or merging of multiple LDT files, can be done by a software goniophotometer. 20 merged headlamps were placed randomly on roads across the entire housing estate model.

Obtrusive light represents a total luminous flux that spreads to the upper half-space and therefore increases sky brightness. It is formed by direct and indirect (reflected) luminous flux from the terrain and particular objects. The most important thing is the evaluation of the luminous flux that is distributed directly to the upper half-space by ULR, see equation 2 below:

$$
U L R=\frac{U L O R}{U L O R+D L O R}
$$

where

ULR proportional direct luminous flux radiated to the top of the half-space;

$U L O R \quad$ luminous flux radiated directly from the luminaire to the top of the half-space;

$D L O R \quad$ luminous flux reflected from the surfaces of the surrounding objects;

$U L O R+D L O R \quad$ total luminous flux radiated to the top of the half-space. 
Table 2 - Parameters of obtrusive light sources in the model

\begin{tabular}{|c|c|c|c|c|c|c|}
\hline $\begin{array}{l}\text { Source of obtrusive } \\
\text { light }\end{array}$ & $\begin{array}{l}\text { System } \\
\text { power } \\
\text { (kW) }\end{array}$ & $\begin{array}{l}\text { System } \\
\text { luminous } \\
\text { flux }(\mathrm{klm})\end{array}$ & $\begin{array}{l}\text { ULOR } \\
(\mathrm{klm})\end{array}$ & $\begin{array}{l}\text { DLOR } \\
(\mathrm{klm})\end{array}$ & $\begin{array}{l}\text { ULOR } \quad+ \\
\text { DLOR } \\
(\mathrm{klm})\end{array}$ & $\begin{array}{l}\text { ULOR }+ \\
\text { DLOR } \\
(\%)\end{array}$ \\
\hline & 16,8 & 846 & 143,8 & 48,2 & 192 & 22,7 \\
\hline & 5,5 & 575 & 0 & 36,2 & 36,2 & 6,3 \\
\hline & - & 102,4 & 39 & 5,4 & 44,4 & 43,4 \\
\hline & - & 5,86 & 2 & 0,3 & 2,3 & 38,6 \\
\hline $3=$ & - & 29,4 & 1,3 & 3 & 4,3 & 14,6 \\
\hline Total values & - & 1558,7 & 186,1 & 93,1 & 279,2 & 17,9 \\
\hline
\end{tabular}

From the table it is apparent that by use of the LED lighting system we limit the input to $1 / 3$ of the original lighting system with HPS. This results in a reduction in the overall luminous flux of the lighting system from $846 \mathrm{klm}$ to $575 \mathrm{klm}$. If we look at the amount of luminous flux to the upper half-space, there is more than fivefold decrease from $192 \mathrm{klm}$ to $36,2 \mathrm{klm}$. Importantly, in LED lighting systems, the luminous flux into the upper half-space only gets as a reflection of the road, grassy areas and building facades, as shown in Table 3, where we see the distribution curves of all sources of obtrusive light in the housing estate model. If we compare the LED system with the billboards system, it is clear that 20 billboards emit more disturbing light than 141 public lighting fixtures, specifically billboards emit $44,4 \mathrm{klm}$. We must not forget the radiation from windows and cars. 217 windows emit $2,3 \mathrm{klm}$ and 20 cars $4,3 \mathrm{klm}$. All the radiation characteristics of the above-mentioned obtrusive light sources are shown in the following table. There is also quantified both direct and total luminous flux of lighting systems in both percent and luminous flux $(\mathrm{klm})$. 
Table 3 - Distribution curves of light sources into the upper half-space

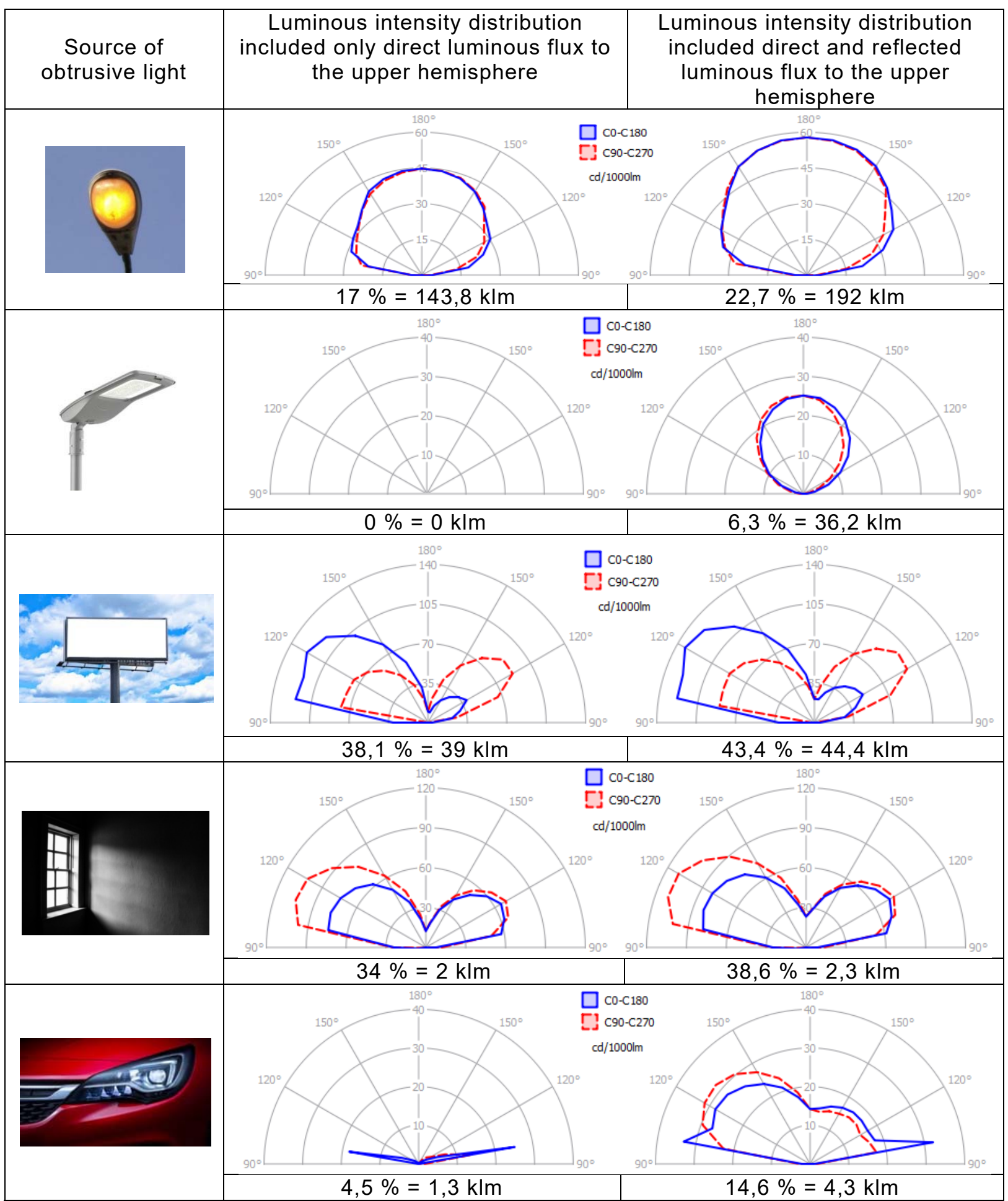

\section{Conclusion}

From the above we can conclude that the luminous flux emitted to the upper half-space is not only from the lighting fixtures but also from other more or less important light sources. This article presents a relatively easy to use tool using which it is possible to quantify obtrusive light based on light-technical calculations. It is not only the calculation of the total luminous flux, but also the directional characteristics of entire cities (or lighting systems), which can be presented, for example, in the LDT file and then used, in addition to the aforementioned quantification, to calculate the flux spread in the atmosphere. 


\section{Acknowledgment}

Work is partially supported by Grants SGS SP2019/143 - BroadbandLIGHT - Public Lighting in SMART City and VI20172019071 - Analysis of Visibility of Transport Infrastructure for Safety Increasing during Night, Sunrise and Sunset.

\section{References}

[1] BRAINARD, G.C. 2001. Action Spectrum for Melatonin Regulation in Humans: Evidence for a Novel Circadian Photoreceptor. Journal of Neuroscience., 21 (16), 6405-6412

[2] STEVENS, R.G. 2014. Breast Cancer and Circadian Disruption From Electric Lighting in the Modern World. CA Cancer Journal for Clinicians., 64 (3), 207-218

[3] NOVAK, T. 2014. Classification of environmental zones in the Czech Republic. Lighting Research and Technology., 46 (2), 93-100.

[4] NAGARE, R. 2019. Effect of White Light Devoid of "Cyan" Spectrum Radiation on Nighttime Melatonin Suppression Over a 1-h Exposure Duration. Journal of Biological Rhythms., 34 (2), 195-204.

[5] NOVAK, T. 2010. Public lighting part measurement for night sky glare increasing before and after switching off big area (Liberec district in the Czech Republic). Proceedings of the 11th International Scientific Conference Electric Power Engineering 2010., 857-861.

[6] DOSTAL, F. 2010. Long-term measurements of night sky illuminance. 9th Conference on Environment and Electrical Engineering, EEEIC 2010., 411-414.

[7] BECAK, P. 2018. Radiation of the Luminous Flux into the Upper Half-Space in Wils Building Design. 7th Lighting Conference of the Visegrad Countries, LUMEN V4 2018 Proceedings., 55-59. 